\title{
Colorectal Endoscopic Submucosal Dissection in a Western Center: Analysis of Outcomes and Safety Profile
}

\author{
João Santos-Antunes ${ }^{\mathrm{a}, \mathrm{c}}$ Margarida Marques ${ }^{\mathrm{a}}$ Rui Morais $^{\mathrm{a}}$ Fátima Carneiro $^{\mathrm{b}, \mathrm{c}}$ \\ Guilherme Macedo ${ }^{a}$ \\ a Department of Gastroenterology, Faculty of Medicine, Centro Hospitalar S. João, Porto, Portugal; 'b Department of \\ Pathology, Faculty of Medicine, Centro Hospitalar S. João, Porto, Portugal; ' Ipatimup/i3S (Instituto de Investigação e \\ Inovação em Saúde da Universidade do Porto), Porto, Portugal
}

\section{Keywords}

Endoscopic submucosal dissection · Colorectal lesions · Western series · Laterally spreading tumour · Colorectal endoscopic submucosal dissection

\section{Abstract}

Introduction: Endoscopic submucosal dissection (ESD) is a well-established endoscopic technique for the treatment of gastrointestinal lesions. Colorectal ESD outcomes are less reported in the Western literature, and Portuguese data are still very scarce. Our aim was to describe our experience on colorectal ESD regarding its outcomes and safety profile. Methods: We conducted a retrospective evaluation of recorded data on ESDs performed between 2015 and 2020. Only ESDs performed on epithelial neoplastic lesions were selected for further analysis. Results: Of a total of 167 colorectal ESDs, 153 were included. Technical success was achieved in 147 procedures (96\%). The lesions were located in the coIon $(n=24)$ and rectum $(n=123)$. The en bloc resection rate was $92 \%$ and $97 \%$, the $\mathrm{R} 0$ resection rate was $83 \%$ and $82 \%$, and the curative resection rate was $79 \%$ and $78 \%$ for the coIon and the rectum, respectively. The need for a hybrid tech- nique was the only risk factor for piecemeal or $\mathrm{R} 1$ resection. We report a perforation rate of $3.4 \%$ and a $4.1 \%$ rate of delayed bleeding; all the adverse events were manageable endoscopically, without the need of blood transfusions or surgery. Most of the lesions were laterally spreading tumours of the granular mixed type (70\%), and $20 \%$ of the lesions were malignant ( $12 \%$ submucosal and $8 \%$ intramucosal cancer). Conclusion: Our series on colorectal ESD reports a very good efficacy and safety profile. This technique can be applied by endoscopists experienced in ESD.

(C) 2021 Sociedade Portuguesa de Gastrenterologia Published by S. Karger AG, Basel

Dissecção endoscópica da submucosa em lesões do colon e recto num centro ocidental: análise de resultados e perfil de segurança

\section{Palavras Chave}

Dissecção endoscópica da submucosa - Lesões do colon e recto - Série ocidental - Laterally spreading tumour. Dissecção endoscópica da submucosa colorectal karger@karger.com www.karger.com/pjg

Karger ${ }^{\prime}$ '

BOPEN ACCESS (c) 2021 Sociedade Portuguesa de Gastrenterologia Published by S. Karger AG, Basel

This is an Open Access article licensed under the Creative Commons Attribution-NonCommercial-4.0 International License (CC BY-NC) (http://www.karger.com/Services/OpenAccessLicense), applicable to the online version of the article only. Usage and distribution for commercial purposes requires written permission.
Correspondence to:

João Santos-Antunes, joao.claudio.antunes@gmail.com 


\section{Resumo}

Introdução: A dissecção endoscópica da submucosa é uma técnica com comprovada eficácia para o tratamento das lesões do tracto digestivo. As dissecções endoscópicas da submucosa de lesões do colon ou recto são menos reportadas na literatura ocidental, e dados Portugueses publicados são escassos. O nosso objectivo foi reportar a eficácia e o perfil de segurança da nossa série nestas lesões. Métodos: Avaliação retrospetiva das dissecções realizadas entre 2015 e 2020, relativamente a lesões epiteliais neoplásicas do colon e recto. Resultados: De um total de 167 lesões colo-rectais, foram incluídas 153 . O sucesso técnico foi de $96 \%$ ( $n=147)$. As lesões estavam localizadas no colon $(n=24)$ e recto $(n=123)$. A taxa de ressecção em bloco foi de $92 \%$ e $97 \%$, de ressecções $\mathrm{R0}$ de $83 \%$ e $82 \%$ e de ressecções curativas foi de $79 \%$ e $78 \%$ no colon e recto respectivamente. A necessidade de realização de técnica híbrida foi o único factor de risco identificado para ressecção em piecemeal ou R1. Obtivemos uma taxa de perfuração de $3.4 \%$ e $4.1 \%$ de hemorragia tardia; todos os eventos adversos foram tratados endoscopicamente, sem necessidade de transfusões sanguíneas ou cirurgia. A maioria das lesões eram lateral spreading tumours do tipo granular nodular misto (70\%), e $20 \%$ das lesões eram malignas (12\% com invasão submucosa, $8 \%$ carcinomas intramucosos). Conclusão: A nossa série de dissecções do colon e recto demonstrou uma muito boa eficácia e excelente perfil de segurança. Este procedimento terapêutico pode ser utilizado por endoscopistas com experiência nesta técnica.

(c) 2021 Sociedade Portuguesa de Gastrenterologia Publicado por S. Karger AG, Basel

\section{Introduction}

Endoscopic submucosal dissection (ESD) is a well-established endoscopic technique for the treatment of gastrointestinal lesions. An en bloc resection of these lesions is preferable, since it allows a precise histological evaluation and leads to lower rates of local recurrence $[1,2]$; therefore, ESD has clear advantages over endoscopic mucosal resection (EMR) in larger lesions. This technique was initially developed for early gastric cancer, but its use has been generalized to other organs, particularly in highvolume centres.

Initially, Eastern studies confirmed its efficacy in the treatment of malignant and premalignant lesions along the gastrointestinal tract [3-5]. We have now robust Western data that also confirm its safety and efficacy, par- ticularly in the stomach [6-9]. Regarding colorectal lesions, the applicability of ESD is still controversial, and European guidelines recommend its use only for lesions with suspicion of malignancy, or those with high-risk morphological features, since piecemeal EMR showed good long-term results in benign colorectal lesions, despite the need for a higher number of procedures [10]. Nevertheless, due to the relatively low number of gastric cancer cases in Europe compared to Eastern countries, endoscopists that aim to be proficient in ESD perform this therapy on rectal lesions at the very beginning of their learning curve. Therefore, Western colorectal series are of paramount importance to address its applicability and efficacy in this setting.

Published data show that Portugal has a very considerable cumulative number of ESDs among Western countries $[7,8,11-14]$. Despite several series reporting on gastric ESDs, there are no Portuguese series dedicated only to colorectal ESD. Therefore, our aim was to report and discuss the indications, outcomes and safety of colorectal ESD in a high-volume reference Portuguese centre.

\section{Methods}

\section{Patient Selection}

ESD was performed on patients followed up in the outpatient clinic or referred to our centre between July 2015 and October 2020, and the results were now retrospectively evaluated.

Lesions selected for this study included colorectal neoplasia without endoscopic suspicion of deep submucosal invasion and unsuitable for en bloc EMR. In the colon, lesions were selected based on morphological features and on white light and narrowband imaging evaluation. In the rectum, all the lesions unsuitable for en bloc EMR were selected for ESD by protocol. Sessile or large pedunculated lesions could also be selected for ESD if this was considered safer than standard polypectomy. Some of these lesions (nearly 25\%) overlap with our previous global ESD series [8]. ESD has been performed at our centre since 2011, but we decided to include only procedures from 2015 to the present as this represents actual practice and in order to assure greater homogeneity of results, since the ESD team and technique changed in that year. Data regarding recurrence and follow-up are out of the scope of this study and will be published elsewhere [15]. Subepithelial lesions, while treated at our centre, were not included in this analysis.

\section{ESD Technique}

Lesions were evaluated using high-definition endoscopy. ESDs were performed by two endoscopists, J.S.-A. and M.M., with a third person (R.M.) now starting his progression in the learning curve. Before starting ESD, J.S.-A. and M.M. had previous experience in therapeutic endoscopy; M.M. started ESD practice in 2011 and J.S.-A. in 2015, after spending 3 months in Japan learning with Japanese experts, and several ex vivo and in vivo porcine model trainings in national and international meetings. 

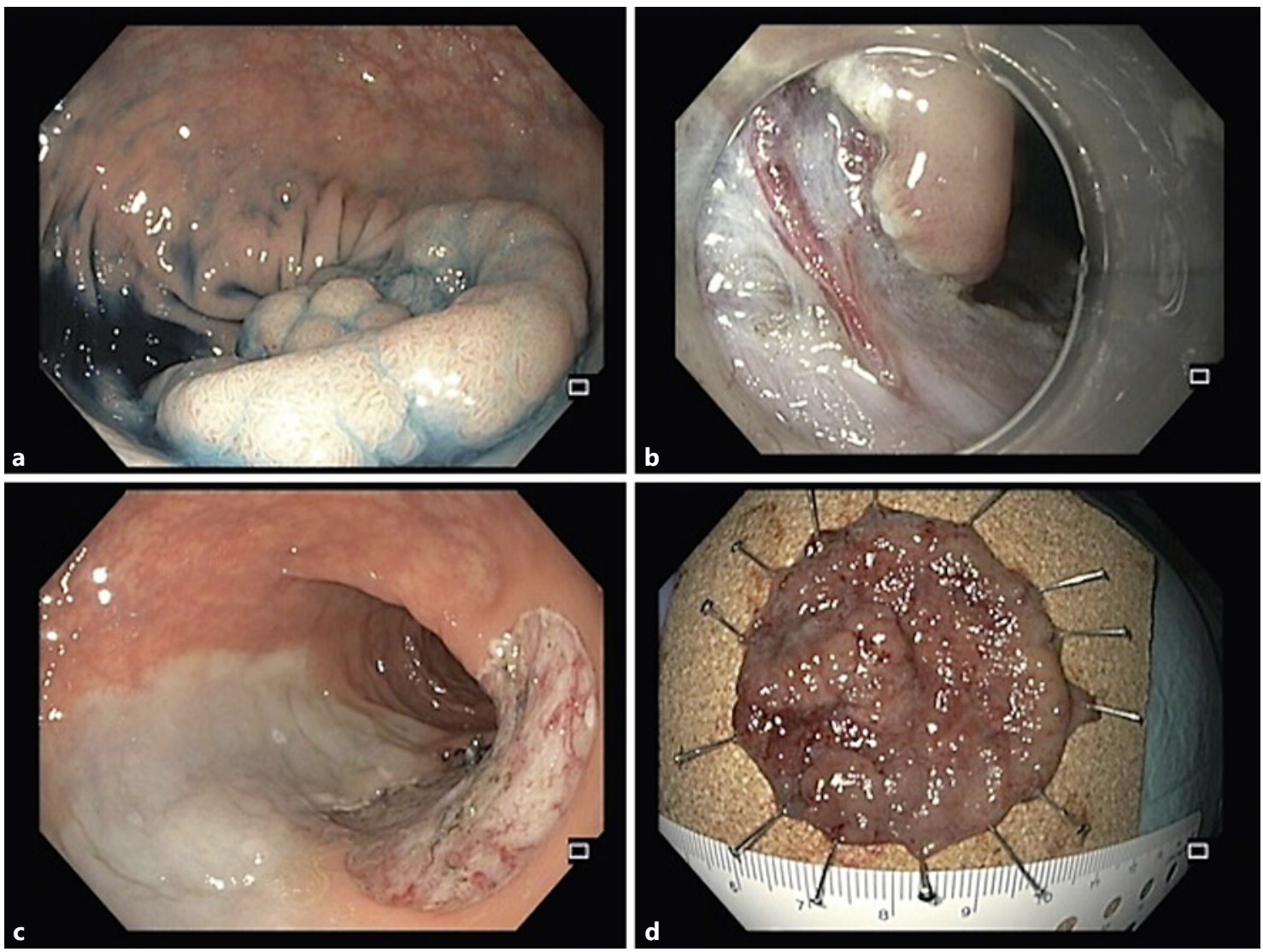

Fig. 1. a Lesion on the sigmoid colon. b Dissection with a DualKnife allows for dissection around perforating vessels and therefore safe coagulation before cutting. c Final endoscopic image after endoscopic submucosal dissection. d Lesion fixed on a cork plate.

Epithelial lesions were assessed using dye chromoendoscopy (indigo carmine or methylene blue) and virtual chromoendoscopy with narrow-band imaging. Routinely, biopsies are not performed or required for the selection of colorectal lesions.

Initially, a mucosal incision was made in the oral or anal side of the lesion, depending on the location, gravity, scope, stability, and lesion assessment in the retroflexed position. Then, the other side of the lesion was approached, with subsequent mucosal incision and submucosal dissection until the margin that had initially been assessed was reached. For large lesions, the pocket creation method was used whenever necessary. A hybrid technique was used only when total submucosal dissection was not achieved with ESD knives. A colloid solution (hydroxyethylamide) with dye (methylene blue or indigo carmine) and diluted adrenaline was used for submucosal lifting. Dissection was performed using Olympus GIF-Q190 scopes and 1.5-mm DualKnives (Olympus ${ }^{\circledR}$, Tokyo, Japan) for mucosal incision and submucosal dissection. Insulated-tip (IT) nano knives (Olympus ${ }^{\circledR}$ ) were used whenever necessary. Erbe VIO-300S electrosurgical units (ERBE ${ }^{\circledR}$ Elektromedizin GmBH, Tübingen, Germany) were used ("endo-cut effect 2 " for mucosal incision and "swift coagulation mode effect 4/30 W" for submucosal dissection and haemostasis). A Coagrasper
(Olympus ${ }^{\circledR}$ ) was used for haemostasis whenever necessary (soft coagulation effect $5 / 80 \mathrm{~W}$ ).

The ESD procedures were performed on an ambulatory basis, with patients discharged after $4 \mathrm{~h}$ of observation in the recovery area.

\section{Histopathological Evaluation}

ESD specimens were sent for pathological evaluation with pins on a cork plate, fixed in formalin. Sectioning at 2-mm intervals was performed to evaluate lateral and vertical margins.

A malignant lesion was considered whenever invasion was present, either intramucosal (Tis lesions, defined as lesions with invasion into the lamina propria or muscularis mucosa) or submucosal (T1 lesions). Due to the clear differences regarding clinical significance, management, and outcomes, we analysed these groups separately.

\section{Definitions and Outcomes}

En bloc resection was considered when the target lesion was retrieved in a single specimen, or considered piecemeal if it was removed in more than one fragment. The procedure was considered to be a failure if the target lesion was not removed. R0 resec- 

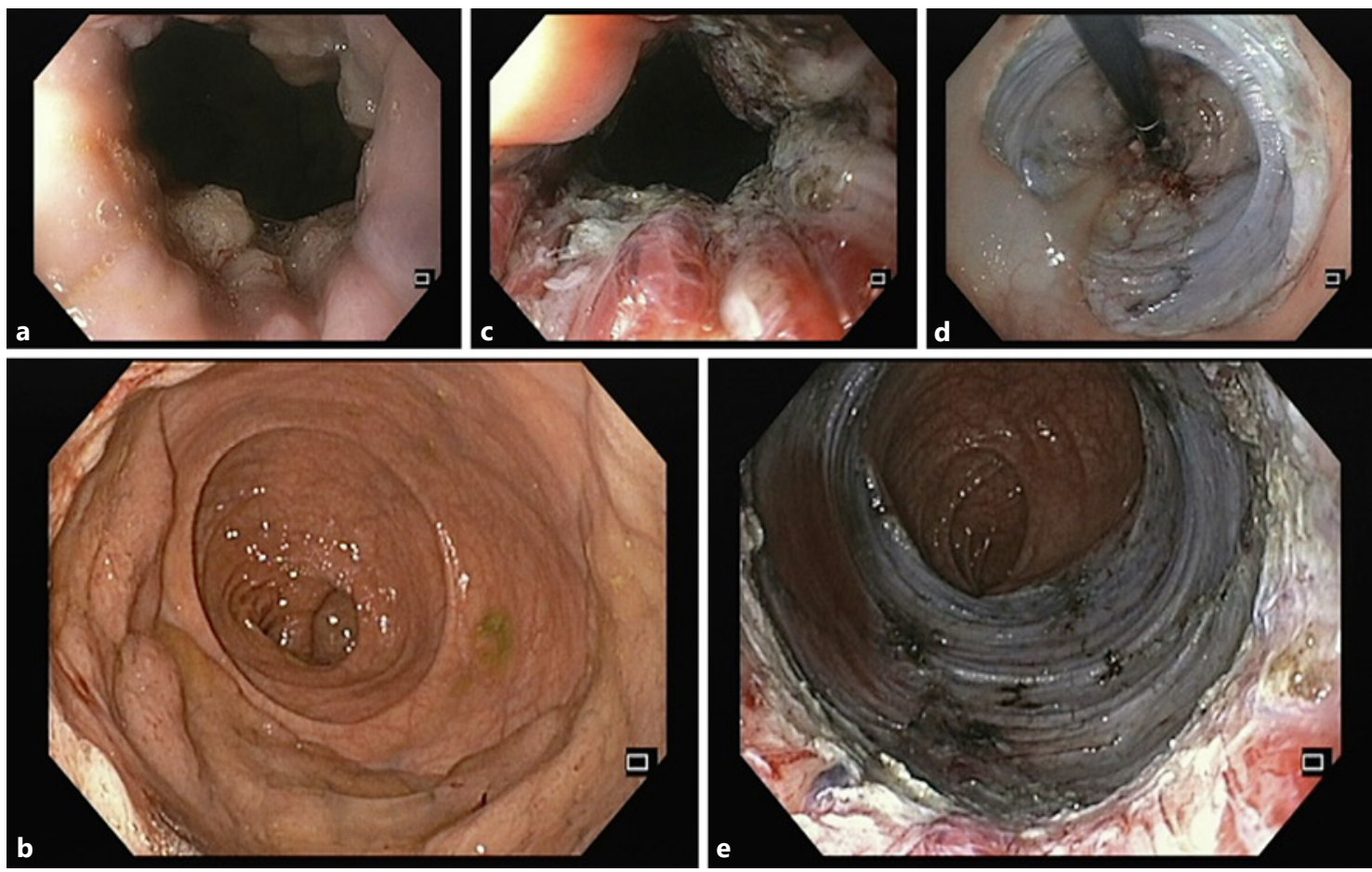

Fig. 2. a Adenoma in the rectum involving the anorectal junction. b Rectal lesion occupying more than $75 \%$ of the circumference. c Dissection in the anal canal. d Retroflexed view of the mucosal defect. e Mucosal defect in the rectum and anal canal.

tion was considered whenever histopathological evaluation showed free horizontal and vertical margins, independently of the dimension of the normal mucosa surrounding the lesion.

Colorectal curative resections were considered if they were R0 with low- or high-grade dysplasia or differentiated-type mucosal or superficial submucosal (SM1, <1,000 $\mu \mathrm{m}$ ) adenocarcinoma without lymphovascular invasion or budding.

Perforation was defined as a defect in the wall allowing visualization of the peritoneum or mesenteric fat. Immediate severe bleeding was defined as bleeding that was not possible to control endoscopically or if it caused hemodynamic instability. Non-severe bleeding during the procedure that was immediately manageable endoscopically was not considered as an adverse event. Delayed bleeding was defined as bleeding from the ESD site, postoperatively.

\section{Statistical Analysis}

All data were collected prospectively in a database. Categorical variables are described as absolute $(n)$ and relative frequencies (\%). Mean and SD or median and percentiles was used for continuous variables as appropriate. When testing a hypothesis about continuous variables, Mann-Whitney non-parametric tests were used as appropriate, taking into account normality assumptions and the number of groups compared. When testing a hypothesis about categorical variables, a $\chi^{2}$ test and Fisher's exact test were used, as appropriate. The significance level used was 0.05 . Statistical analysis was performed using the Statistical Package for the Social Sciences version 22.0 .

\section{Results}

During the period of analysis, 167 colorectal lesions were treated in 167 patients, 96 being male (58\%), with a mean age of $64 \pm 11$ years. The mean lesion size was $44 \pm$ $20 \mathrm{~mm}$ (min. $15 \mathrm{~mm}$, max. $170 \mathrm{~mm}$ ). The median time was 90 min (IQR 25-75\% 60-136 min; min. 10 min, max. $330 \mathrm{~min})$.

The target lesion was not removed (ESD failure) in 6 cases (3.6\%). Thirteen rectal ESDs were performed on subepithelial lesions and 1 lesion was hyperplastic; they were excluded from this study.

Among the remaining procedures $(n=147)$, lesions were located in the caecum $(n=1)$, ascending colon $(n=$ $2)$, hepatic flexure $(n=1)$, transverse colon $(n=1)$, descending colon $(n=2)$, sigmoid colon $(n=17)$, and rectum $(n=123)$ (Fig. 1, 2). The majority of the ESDs were performed using a DualKnife only $(n=113)$, and the IT nano knife was used in combination with a DualKnife in the remaining 34 procedures. Three lesions were removed using the pocket creation technique, and hybrid ESD was used in 8 procedures. Haemostasis was achieved with a DualKnife only in 37 procedures; in the remaining cases, 
Table 1. Relationship between morphology and histology in colonic lesions

\begin{tabular}{llcccc}
\hline & \multicolumn{2}{c}{ Adenocarcinoma } & HGD & LGD & Total \\
\cline { 2 - 5 } & Tis & T1 & & & \\
\hline LSTG-H & 0 & & 1 & 4 & 5 \\
LSTG-NM & 1 & 0 & 0 & 5 & 14 \\
LSTNG-FE & 0 & 1 & 0 & 1 & 1 \\
LSTNG-PD & 0 & & 1 & 1 & 2 \\
Pedunculated & 0 & & 1 & 0 & 1 \\
Sessile & 0 & & 11 & 11 & 24 \\
Total & 2 & & 11 & 1 \\
\hline
\end{tabular}

LSTG-H, laterally spreading tumours of the granular-homogeneous type; LSTG-NM, laterally spreading tumours of the granular-nodular mixed type; LSTNG-FE, laterally spreading tumours of the non-granular-flat elevated type; LSTNG-PD, laterally spreading tumours of the non-granular-pseudodepressed type; HGD, highgrade dysplasia; LGD, low-grade dysplasia.

Table 2. Relationship between morphology and histology in rectal lesions

\begin{tabular}{|c|c|c|c|c|c|c|}
\hline & \multicolumn{2}{|c|}{ Adenocarcinoma } & \multirow[t]{2}{*}{ HGD } & \multirow[t]{2}{*}{ LGD } & \multirow{2}{*}{$\begin{array}{l}\text { Serrated with } \\
\text { dysplasia }\end{array}$} & \multirow[t]{2}{*}{ Total } \\
\hline & Tis & $\mathrm{T} 1$ & & & & \\
\hline LSTG-H & 0 & 1 & 4 & 15 & 2 & 22 \\
\hline LSTG-NM & 9 & 13 & 46 & 21 & 0 & 89 \\
\hline LSTNG-FE & 1 & 1 & 0 & 0 & 0 & 2 \\
\hline LSTNG-PD & 0 & & 0 & 0 & 1 & 1 \\
\hline Pedunculated & 0 & & 2 & 1 & 0 & 3 \\
\hline Sessile & 1 & 1 & 4 & 0 & 0 & 6 \\
\hline Total & 27 & & 56 & 37 & 3 & 123 \\
\hline
\end{tabular}

LSTG-H, laterally spreading tumours of the granular-homogeneous type; LSTG-NM, laterally spreading tumours of the granular-nodular mixed type; LSTNG-FE, laterally spreading tumours of the non-granular-flat elevated type; LSTNG-PD, laterally spreading tumours of the non-granular-pseudodepressed type; HGD, highgrade dysplasia; LGD, low-grade dysplasia.

a Coagrasper was used during dissection or for the coagulation of vessels in the mucosal defect, at the end of the procedure.

We had a total of 5 (3.4\%) perforations, all of a very small size, that were manageable by hemoclips, not precluding the success of the treatment. We had $6(4.1 \%)$ delayed bleedings, all manageable endoscopically; none of them required blood transfusions, and only 1 was admitted. Surgery due to adverse events was not needed in any case, and procedure-related mortality was $0 \%$.

Most of our lesions were laterally spreading tumours of the granular-nodular mixed type (LSTG-NM; $n=103$,
$70 \%)$, the remaining lesions being laterally spreading tumours of the granular-homogeneous type (LSTG-H; $n=$ $27,18 \%$ ), laterally spreading tumours of the non-granularflat elevated type (LSTNG-FE; $n=3,2 \%$ ), and laterally spreading tumours of the non-granular-pseudodepressed type (LSTNG-PD; $n=2,1 \%$ ). ESD was also performed on large pedunculated $(n=5,3 \%)$ or sessile $(n=8,6 \%)$ polyps.

Regarding pathological evaluation, 29 (20\%) were adenocarcinomas (12 intramucosal and 17 submucosal adenocarcinomas [ 5 of them with $>\mathrm{SM} 1$ invasion]), the remaining being high-grade dysplasia $(n=67)$, low-grade dysplasia $(n=48)$, and serrated with dysplasia $(n=3)$. The 
Table 3. Risk factors for piecemeal resection and R1 resection

\begin{tabular}{lcc}
\hline & En bloc vs. piecemeal & R0 vs. R1 resection \\
& resection $(p$ value $)$ & $(p$ value $)$ \\
\hline Mean size, mm & 44 vs. $38(0.439)$ & 42 vs. $52(0.111)$ \\
Mean procedure time, min & 104 vs. $158(0.089)$ & 97 vs. $150(<0.001)$ \\
LST morphology, $\%$ & 0.958 & 0.772 \\
G-H $(n=27)$ & 96 vs. 4 & 85 vs. 15 \\
G-NM $(n=103)$ & 95 vs. 5 & 83 vs. 17 \\
NG-FE $(n=3)$ & 100 vs. 0 & 67 vs. 33 \\
NG-PD $(n=2)$ & 100 vs. 0 & 100 vs. 0 \\
Histology, $\%$ & 0.578 & 0.595 \\
Adenocarcinoma $(n=29)$ & 100 vs. 0 & 90 vs. 10 \\
HGD $(n=67)$ & 94 vs. 6 & 78 vs. 22 \\
LGD $(n=48)$ & 96 vs. 4 & 83 vs. 17 \\
Serrated with dysplasia $(n=3)$ & 100 vs. 0 & 100 vs. 0 \\
Perforation, $\%$ & 0.190 & 1.000 \\
Yes $(n=5)$ & 80 vs. 20 & 80 vs. 20 \\
No $(n=142)$ & 97 vs. 3 & 82 vs. 18 \\
Knife, $\%$ & 0.278 & 0.153 \\
DualKnife $(n=113)$ & 97 vs. 3 & 86 vs. 14 \\
DualKnife + IT nano knife $(n=34)$ & 91 vs. 9 & 71 vs. 29 \\
Hybrid technique, $\%$ & $<0.001$ & 0.003 \\
Yes $(n=8)$ & 50 vs. 50 & 38 vs. 62 \\
No $(n=139)$ & 99 vs. 1 & 85 vs. 15 \\
Local, $\%$ & 0.253 & 1.000 \\
Colon $(n=24)$ & 92 vs. 8 & 83 vs. 17 \\
Rectum $(n=123)$ & 97 vs. 3 & 82 vs. 18 \\
\hline
\end{tabular}

LSTG-H, laterally spreading tumours of the granular-homogeneous type; LSTG-NM, laterally spreading tumours of the granular-nodular mixed type; LSTNG-FE, laterally spreading tumours of the non-granular-flat elevated type; LSTNG-PD, laterally spreading tumours of the non-granular-pseudodepressed type; HGD, highgrade dysplasia; LGD, low-grade dysplasia.

relationship between morphology and histology can be analysed in Tables 1 and 2 .

En bloc resection was achieved in 22 of the 24 lesions in the colon (92\%) and in 119 of the 123 lesions in the rectum (97\%). R0 and curative resection, respectively, was achieved in $83 \%$ and $79 \%$ in the colon and $82 \%$ and $78 \%$ in the rectum. The reasons for non-curative resection among the 141 en bloc-resected specimens were a positive lateral margin $(n=18)$, positive deep margin $(n=2)$, venous permeation $(n=3)$, tumour budding $(n=4)$, and $>$ SM1 invasion $(n=5)$.

Among the $\mathrm{R} 0$ resections, the lesions that did not fulfil the curative criteria were 1 colonic LST with submucosal adenocarcinoma $>$ SM1 and budding (that was operated, without lesion in the surgical specimen - T0N0), 2 SM1 rectal adenocarcinomas with vascular permeation (that were operated, without lesion in the surgical specimen T0N0), $1>$ SM1 rectal submucosal adenocarcinoma (un- der surveillance, no residual lesion after 1 year), 1 SM1 rectal adenocarcinoma with tumour budding (that was operated, without lesion in the surgical specimen T0N0), and 1 rectal LST with submucosal adenocarcinoma $>$ SM1 and budding (that was operated, without lesion in the wall but 1 positive lymph node - T0N1). The only risk factor significantly associated both with piecemeal and $\mathrm{R} 1$ resection was performance of the hybrid technique, while longer procedures were also associated with R1 resections (Table 3).

\section{Discussion}

This is the first Portuguese colorectal ESD series, demonstrating that this technique is safe and effective for the treatment of colorectal neoplasia. Colorectal ESD is a controversial issue in the field of gastrointestinal endos- 
copy. The arguments against universal ESD are that the majority of the lesions can be managed by piecemeal EMR, and that ESD has the potential for a higher frequency of adverse events. The ACE multicentre study [16] reported a $16 \%$ recurrence among 799 colorectal lesions removed by EMR; the authors stated that $98 \%$ of the patients were free of disease without the need of surgery at 16 months, even if repeated endoscopic procedures were required. In another study [17], a 6-month recurrence of $19.4 \%$ was reported and the Sydney EMR recurrence tool was proposed, in which 3 risk factors (size $>40 \mathrm{~mm}$, intraprocedural bleeding, and high-grade dysplasia) were identified; the absence of any of these had a negative predictive value of $91 \%$ for 6 -month recurrence, and the first follow-up could be performed only 18 months after the EMR, contrasting to the 6-month period for the remaining lesions.

On the other hand, some Western colleagues are against the use of piecemeal resection in this context [18]. They argue that the risk of missing a focal invasion, budding, or a tumour embolus because the fragment in question was not recovered is unacceptable and could have serious consequences for the patient, who will not benefit from complementary treatment. Furthermore, the risk of ESD will probably be lowering with accumulating experience, and more than $95 \%$ of perforations are treated endoscopically, not leading to surgery. In fact, some Japanese multicentre studies do not show any differences regarding adverse events between ESD and EMR [19]. ESD leads to much higher rates of en bloc resection and curative resections and lower rates of recurrence [1]. Our data support that this technique can be extremely safe in experienced hands; all the bleedings and perforations were manageable endoscopically, without the need of surgery, and with no mortality.

European guidelines stated that ESD should be the first option for colorectal non-granular/depressed lesions above $20 \mathrm{~mm}$ [10]. In fact, this is a well-accepted strategy for this kind of lesions, due to the high risk of harbouring malignancy. We only had 5 cases of non-granular lesions removed by ESD, 3 of them having been adenocarcinomas. The most controversial issue is the treatment of LSTG-NM, which have a moderate-to-high risk of advanced histology, particularly below the large nodules, and are also the most prevalent morphology. Among our LSTG-NM lesions, we had 9 adenocarcinomas or highgrade dysplasias among 14 colonic lesions, and 68 among 89 rectal lesions. Despite the benign nature of the majority of these lesions, the possibility of malignancy is higher than in granular homogeneous lesions; furthermore, our

Colorectal Endoscopic Submucosal

Dissection in a Western Center experience with LSTNG lesions is that they frequently have significant submucosal fibrosis (even in benign lesions), which makes ESD much more challenging, particularly in the colon. We think that LSTG-NM should be the first colorectal lesions resected in the learning curve of colorectal ESD, then progressing to non-granular lesions. A recent Italian multicentre study on LSTG-NM [20] showed that non-rectal lesions below $4 \mathrm{~cm}$ in size have a risk of submucosal invasive cancer (SMIC) of 5\%, and they can be managed by piecemeal EMR. On the other hand, rectal lesions above $4 \mathrm{~cm}$ should always be resected en bloc, due to the $22 \%$ risk of SMIC (NNT of 5) versus the $8 \%$ risk of SMIC in rectal lesions below $4 \mathrm{~cm}$. We agree partially with this strategy, since we also defend that en bloc resection should always be attempted in the rectum, even in lesions below $4 \mathrm{~cm}$, for two main reasons. The first reason is that we could spare $8 \%$ of these patients from aggressive and mutilating surgeries, which we deem important enough to consider ESD instead of piecemeal EMR [21]. The second is that, for experienced endoscopists, ESD for rectal lesions below $4 \mathrm{~cm}$ would certainly have an excellent safety profile and a very high rate of $\mathrm{R} 0$ resections.

Our R0 resection rate is significantly lower than our en bloc resection rate, a positive lateral margin being by far the most frequent reason for not achieving total resection. We believe that most of these "positive margins" are in lesions that have in fact been completely resected, since the lateral margins are easily identified during ESD, and the use of the DualKnife allows us to be completely confident that the mucosal incision is being performed in normal tissue. In contrast to the stomach, we usually leave only a few millimetres of normal mucosa outside de lesion; this, in addition with the lesion's contraction after its extraction, makes fixation in the cork plate difficult. The pins can therefore damage the lateral margin of the lesions, and a false $\mathrm{R} 1$ resection diagnosis will consequently be made.

Among rectal lesions, those situated in the anorectal junction could be particularly challenging. A recent Australian study [22] showed that these lesions could be safely managed by piecemeal EMR, with recurrence rates of $15 \%$ in the first surveillance colonoscopies. These data came from centres very experienced in piecemeal EMR, and we think that the $98 \%$ rate of success that was achieved by these authors would be hardly reproducible at other centres, even among endoscopists performing colorectal EMR. We think that ESD is an extremely valuable technique in this particular area. The anal mucosa produces a very good lifting, and mucosal incision and submucosal 
dissection with a needle-type knife, such as the DualKnife, allows a very precise and safe submucosal dissection in this topography, even in lesions located on the haemorrhoidal plexus and dentate line (Fig. 2); according to our experience, this location does not add much more complexity for endoscopists experienced in rectal ESD [23].

In conclusion, we demonstrated that colorectal ESD can be safely done in Portugal by endoscopists experienced in ESD, preferably in high-volume centres. In fact, the rate of adverse events was not very different from those reported in colorectal EMR studies. Furthermore, there are ongoing studies [24] to verify whether ESD is also more cost-effective than piecemeal EMR, due to the lower number of procedures that are needed than in patients treated with ESD. Adding to the higher rate of R0 resections, if we achieve a rate of adverse events and costeffectiveness similar to those of piecemeal EMR, we could attain in the near future a paradigm shift regarding the treatment of these lesions.

\section{Statement of Ethics}

Written consent was obtained before the realization of the ESDs. Consent for this study was not obtained, due to the noninterventional/retrospective nature of the analysis.

\section{Conflict of Interest Statement}

The authors declare that there is no conflict of interest.

\section{Funding Sources}

There are no funding sources to declare.

\section{Author Contributions}

J.S.-A. performed ESD procedures, collected the data, and wrote the manuscript. M.M. performed ESD procedures and provided scientific revision. R.M. provided scientific revision. F.C. was the main one responsible for the pathological analysis of ESD specimens. G.M. provided the final critical revision.

\section{References}

1 Fujiya M, Tanaka K, Dokoshi T, Tominaga $\mathrm{M}$, Ueno N, Inaba Y, et al. Efficacy and adverse events of EMR and endoscopic submucosal dissection for the treatment of colon neoplasms: a meta-analysis of studies comparing EMR and endoscopic submucosal dissection. Gastrointest Endosc. 2015 Mar; 81(3):583-95.

2 Park YM, Cho E, Kang HY, Kim JM. The effectiveness and safety of endoscopic submucosal dissection compared with endoscopic mucosal resection for early gastric cancer: a systematic review and metaanalysis. Surg Endosc. 2011 Aug;25(8):2666-77.

3 Tsujii Y, Nishida T, Nishiyama O, Yamamoto K, Kawai N, Yamaguchi S, et al. Clinical outcomes of endoscopic submucosal dissection for superficial esophageal neoplasms: a multicenter retrospective cohort study. Endoscopy. 2015 Sep;47(9):775-83.

4 Hayashi Y, Shinozaki S, Sunada K, Sato H, Miura Y, Ino Y, et al. Efficacy and safety of endoscopic submucosal dissection for superficial colorectal tumors more than $50 \mathrm{~mm}$ in diameter. Gastrointest Endosc. 2016 Mar; 83(3):602-7.

5 Shin KY, Jeon SW, Cho KB, Park KS, Kim ES, Park CK, et al. Clinical outcomes of the endoscopic submucosal dissection of early gastric cancer are comparable between absolute and new expanded criteria. Gut Liver. 2015 Mar; $9(2): 181-7$.
6 Tate DJ, Klein A, Sidhu M, Desomer L, Awadie H, Lee EY, et al. Endoscopic submucosal dissection for suspected early gastric cancer: absolute versus expanded criteria in a large Western cohort (with video). Gastrointest Endosc. 2019 Sep;90(3):467-79.e4.

7 Costa RS, Ferreira A, Leal T, Costa D, Rolanda C, Gonçalves R. Endoscopic Submucosal Dissection for the Treatment of Superficial Epithelial Gastric Neoplasia in a Portuguese Centre. GE Port J Gastroenterol. 2019 Mar;26(2): 90-8.

8 Santos-Antunes J, Baldaque-Silva F, Marques M, Lopes J, Carneiro F, Macedo G. Real-life evaluation of the safety, efficacy and therapeutic outcomes of endoscopic submucosal dissection in a Western tertiary centre. United European Gastroenterol J. 2018 Jun;6(5):7029.

9 Pimentel-Nunes P, Libânio D, Dinis-Ribeiro M. Evaluation and Management of Gastric Superficial Neoplastic Lesions. GE Port J Gastroenterol. 2017 Jan;24(1):8-21.

10 Pimentel-Nunes P, Dinis-Ribeiro M, Ponchon T, Repici A, Vieth M, De Ceglie A, et al. Endoscopic submucosal dissection: European Society of Gastrointestinal Endoscopy (ESGE) Guideline. Endoscopy. 2015 Sep; 47(9):829-54.

11 Santos-Antunes J, Marques M, Macedo G. Endoscopic Submucosal Dissection: experience in Portugal. GE Port J Gastroenterol. 2020 Jan;27(1):71-2.
12 Pimentel-Nunes P, Mourão F, Veloso N, et al. Long-term follow-up after endoscopic resection of gastric superficial neoplastic lesions in Portugal. Endoscopy. 2014;46(11):933-40.

13 Rodrigues J, Carmo J, Carvalho L, Barreiro P, Chagas C. Endoscopic submucosal dissection for gastrointestinal superficial lesions: initial experience in a single Portuguese center. GE Port J Gastroenterol. 2015 Jul;22(5):190-7.

14 Libânio D, Pimentel-Nunes P, Afonso LP, Henrique R, Dinis-Ribeiro M. Long-term outcomes of gastric endoscopic submucosal dissection: focus on metachronous and noncurative resection management. GE Port J Gastroenterol. 2017 Jan;24(1):31-9.

15 Santos-Antunes J, Marques M, Morais, Carneiro F, et al. Very low rate of residual neoplasia after non-curative Endoscopic Submucosal Dissection: a western single-center experience. Eur J Gastroenterol Hepatol [Accepted for publication].

16 Moss A, Williams SJ, Hourigan LF, Brown G, Tam W, Singh R, et al. Long-term adenoma recurrence following wide-field endoscopic mucosal resection (WF-EMR) for advanced colonic mucosal neoplasia is infrequent: results and risk factors in 1000 cases from the Australian Colonic EMR (ACE) study. Gut. 2015 Jan;64(1):57-65. 
17 Tate DJ, Desomer L, Klein A, Brown G, Hourigan LF, Lee EY, et al. Adenoma recurrence after piecemeal colonic EMR is predictable: the Sydney EMR recurrence tool. Gastrointest Endosc. 2017 Mar;85(3):647-56.e6.

18 Pioche M, Rivory J, Jérémie J. Colorectal endoscopic submucosal dissection for all LSTs: histological information loss due to piecemeal EMR is no longer acceptable. Endosc Int Open. 2019 Oct;7(10):E1195-6.

19 Oka S, Tanaka S, Saito Y, Iishi H, Kudo SE, Ikematsu H, et al.; Colorectal Endoscopic Resection Standardization Implementation Working Group of the Japanese Society for Cancer of the Colon and Rectum, Tokyo, Japan. Local recurrence after endoscopic resec- tion for large colorectal neoplasia: a multicenter prospective study in Japan. Am J Gastroenterol. 2015 May;110(5):697-707.

20 D'Amico F, Amato A, Trovato C, et al. Risk of covert submucosal cancer in patients with granular mixed laterally spreading tumors. Clin Gastroenterol Hepatol. 2020 Online ahead of print.

21 Santos-Antunes J, Macedo G. Submucosal cancer in granular mixed type laterally spreading tumors - is universal ESD an acceptable approach in these lesions? Clin Gastroenterol Hepatol. 2020 [Online ahead of print].

22 Shahidi N, Sidhu M, Vosko S, van Hattem WA, Bar-Yishay I, Schoeman S, et al. Endo- scopic mucosal resection is effective for laterally spreading lesions at the anorectal junction. Gut. 2020 Apr;69(4):673-80.

23 Santos-Antunes J, Marques M, Carneiro F, et al. Choosing the best approach for laterally spreading lesions at the anorectal junction. Gut. 2020 [Online ahead of print].

24 Backes Y, Moons LM, van Bergeijk JD, Berk L, Ter Borg F, Ter Borg PC, et al. Endoscopic mucosal resection (EMR) versus endoscopic submucosal dissection (ESD) for resection of large distal non-pedunculated colorectal adenomas (MATILDA-trial): rationale and design of a multicenter randomized clinical trial. BMC Gastroenterol. 2016 May;16(1):56. 